\title{
BILANGAN TERHUBUNG TITIK PELANGI PADA GRAF KUADRATIK DAN GRAF GARIS DARI GRAF KEMBANG API
}

\author{
Brella Glysentia Vilgalita, Yundari, Fransiskus Fran
}

\begin{abstract}
INTISARI
Pewarnaan titik pada graf $G=(V, E)$ dikatakan terhubung titik pelangi, jika untuk setiap dua titik u dan $v$ di $V(G)$ terdapat lintasan $u-v$ dengan semua titik internal memiliki warna berbeda. Bilangan terhubung titik pelangi $G$ dinotasikan dengan $\operatorname{rvc}(G)$, adalah minimal banyaknya warna yang dibutuhkan untuk membuat $G$ terhubung titik pelangi. Pada penelitian ini dibahas tentang bilangan terhubung titik pelangi pada graf kuadratik dari graf kembang api $F_{n, 3}^{2}$ dan graf garis dari graf kembang api $L\left(F_{n, 3}\right)$ dengan $n \in \mathbb{N}$ dan $n \geq 2$. Graf kembang api $F_{n, 3}$ merupakan graf yang dibentuk dari graf lintasan dan graf bintang dengan $n \in \mathbb{N}$ dan $n \geq 2$. Berdasarkan hasil penelitian diperoleh bilangan terhubung titik pelangi pada graf kuadratik dari graf kembang api adalah $\operatorname{rvc}\left(F_{n, 3}^{2}\right)=\left\lfloor\frac{n}{2}\right\rfloor+1$ dan graf garis dari graf kembang api adalah $\operatorname{rvc}\left(L\left(F_{n, 3}\right)\right)=2 n-1$.
\end{abstract}

Kata Kunci: pewarnaan titik pelangi, terhubung titik pelangi, titik internal.

\section{PENDAHULUAN}

Pewarnaan titik pada graf $G$ adalah pemberian warna pada titik-titik dalam graf $G$, dimana setiap titik hanya memiliki satu warna dan titik yang bertetangga diwarnai dengan warna yang berbeda. Indeks kromatik $G$ dinotasikan dengan $\chi(G)$ adalah minimal banyaknya warna yang dibutuhkan untuk mewarnai graf $G$. Dalam teori graf pewarnaan titik mengalami perkembangan, salah satunya pewarnaaan titik pelangi. Pewarnaan titik pelangi pada graf diperkenalkan pada tahun 2009 [1]. Pewarnaan titik pelangi yaitu pewarnaan titik pada $G$ yang menyebabkan $G$ terhubung titik pelangi. Graf $G$ terhubung titik pelangi jika titik internal pada lintasan $u-v$ untuk setiap $u, v \in V(G)$ memiliki warna yang berbeda. Bilangan terhubung titik pelangi pada graf dinotasikan sebagai $\operatorname{rvc}(G)$, yaitu minimal banyaknya warna yang dibutuhkan untuk membuat $G$ terhubung titik pelangi [1].

Pada penelitian sebelumnya tentang konsep keterhubungan titik pelangi telah diterapkan pada graf pensil [2], graf sisir [10] dan graf bunga [11]. Konsep bilangan terhubung titik pelangi tidak hanya diteliti pada graf khusus saja, tetapi juga dapat diteliti pada hasil pembentukan graf baru terhadap dua buah graf atau lebih sebagai contoh, yaitu graf kembang api. Graf kembang api $F_{n, k}$ merupakan graf yang dibentuk dari graf lintasan $P_{n}$ dan graf bintang $S_{k}$ dengan $n \geq 2, k=3$ dan $n \in \mathbb{N}$. Dari graf kembang api yang merupakan graf awal tersebut kemudian dibentuk menjadi graf baru yaitu graf kuadratik $F_{n, k}^{2}$ dan graf garis $L\left(F_{n, k}\right)$ dari graf kembang api dengan $n \geq 2, k=3$ dan $n \in \mathbb{N}$.

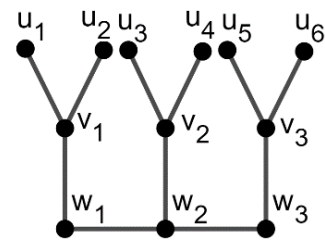

(a)

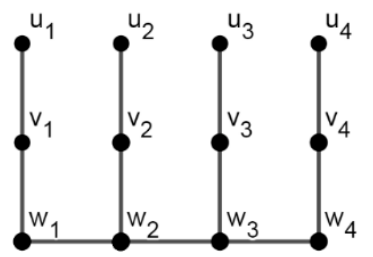

(b)

Gambar 1 (a) Graf Kembang Api $F_{3,4}$ dan (b) Graf Kembang Api $F_{4,3}$ 


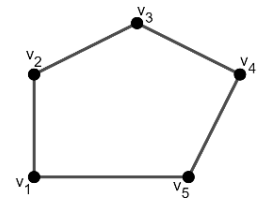

(a)

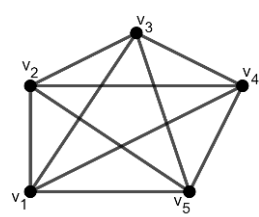

(b)

Gambar 2 (a) Graf $G$ dengan 5 Tititk dan (b) Graf $G^{2}$ dengan 5 Titik

\section{GRAF KEMBANG API, GRAF KUADRATIK DAN GRAF GARIS}

Graf $G$ adalah pasangan himpunan $(V(G), E(G))$ dengan $V(G)$ adalah himpunan tak kosong dari titik dan $E(G)$ adalah himpunan (mungkin kosong) pasangan tak berurutan dari titik-titik yang berbeda dari $V(G)$ yang disebut sisi [3]. Dalam penelitian ini titik pada graf dinyatakan dengan $u_{i}$ atau $v_{i}$ untuk $i \in \mathbb{N}$. Sedangkan dua titik yang dihubungkan oleh sisi dinyatakan dengan $e=(u, v)$ atau $e=u v$. Beberapa istilah yang berkaitan dengan graf yang digunakan dalam penelitian ini yaitu bertetangga (adjacent), bersisian (incident) dan derajat [3]. Dua buah titik pada graf $G$ dikatakan bertetangga jika keduannya terhubung langsung dengan sebuah sisi. Lebih lanjut, titik $u$ dan sisi $u v$ di $G$ dikatakan bersisian karena titik terhubung langsung oleh satu sisi maka satu titik dan satu sisi tersebut dikatakan bersisian. Dengan kata lain, titik $u, v$ dikatakan bertetangga jika $e=(u, v)$ di $G$. Derajat dari suatu titik $v$ pada graf $G$ adalah banyaknya sisi di $G$ yang bersisian dengan titik $v$ dan ditulis dengan $\operatorname{deg}(v)$. Berikut diberikan graf khusus yang dibahas pada Definisi 1.

Definisi 1 [7] Graf kembang api $F_{n, k}$ dengan $n, k \in \mathbb{N}$ adalah graf yang diperoleh dari $n$ buah graf bintang dengan cara menghubungkan sebuah daun dari setiap $S_{k}$ melalui sebuah graf lintasan $P_{n}$.

Berdasarkan Gambar 1 (a), menunjukkan graf bergerak terhadap $k$ pada graf bintang dan $n=3$, sedangkan pada Gambar 1 (b), menunjukkan graf bergerak terhadap $n$ pada graf lintasan dan $k=3$. Pada kajian ini, dikaji mengenai graf kembang api $F_{n, 3}$ dengan $n \geq 2$ dan memiliki $3 n$ titik. Graf kembang api memiliki diameter, yaitu:

$$
\operatorname{diam}\left(F_{n, 3}\right)=n+3
$$

Suatu graf dapat dibuat graf baru dengan menggunakan konsep graf kuadratik dan graf garis. Penjelasan mengenai kedua graf tersebut diberikan pada Definisi 2 dan Definisi 3.

Definisi 2 [4] Misalkan $G=(V(G), E(G))$ graf hingga dan terhubung, graf kuadratik $G^{2}$ adalah graf yang diperoleh dari $G$ dengan menambahkan sisi diantara dua titik yang memiliki jarak 2 di $G$.

Representasi dari graf $G$ dapat dilihat pada Gambar 2. Pada Gambar 2, dapat dilihat perbedaan dari graf $G$ dan graf kuadratik dari graf $G$. Gambar 2 (a) merupakan gambar graf $G$ dan Gambar 2 (b) merupakan gambar graf kuadratik $\left(G^{2}\right)$ dari graf $G$.

Definisi 3 [5] Misalkan $G=(V(G), E(G))$ graf hingga dan terhubung. Graf garis $L(G)$ merupakan graf dengan $V(L(G))=E(G)$ dan dua titik di $L(G)$ akan bertetangga jika dan hanya jika sisi-sisi yang bersesuaian saling bertetangga di $G$.

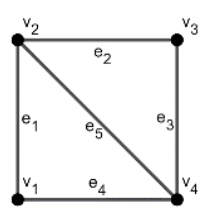

(a)

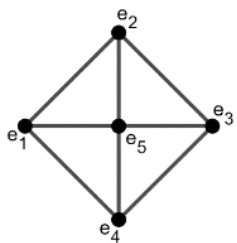

(b)

Gambar 3 (a) Graf $G$ dengan 4 Tititk dan (b) Graf $L(G)$ dengan 5 Titik 


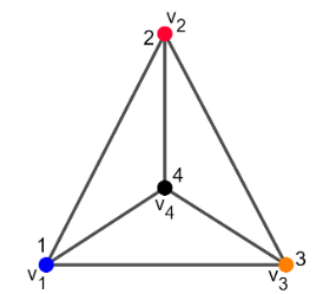

\section{Gambar 4 Pewarnaan Titik Graf $G$}

\section{PEWARNAAN TITIK PADA GRAF}

Pewarnaan titik pada graf merupakan pemetaan dari himpunan titik ke himpunan warna atau himpunan bilangan asli $\{1,2, \ldots, k\}$. Adapun definisi pewarnaan titik dibahas pada Definisi 4 .

Definisi 4 [6] Misalkan $G=(V(G),(E(G))$ terhubung dan tak trivial. Didefinisikan pewarnaan titik dari $G$, yaitu $c: V(G) \rightarrow\{1,2,3, \ldots, k\}$ dan $k \in \mathbb{N}$ sedemikian sehingga $c(u) \neq c(v)$ jika u dan $v$ bertetangga di $G$

Pada pewarnaan titik di $G$ dikaji terkait minimal banyaknya warna dalam pewarnaan. Penjelasan lebih lengkap mengenai minimal banyaknya warna diberikan pada Definisi 5.

Definisi 5 [6] Bilangan kromatik dari graf $G$, dinyatakan dengan $\chi(G)$ adalah minimal banyaknya warna yang digunakan untuk pewarnaan titik pada graf $G$.

Kemudian dari Definisi 4 dan Definisi 5, diberikan contoh graf untuk pewarnaan titik dan bilangan kromatik, sebagai berikut.

Contoh 6 Diberikan sebuah graf $G=\left(\left\{v_{1}, v_{2}, v_{3}, v_{4}\right\},\left\{e_{1}, e_{2}, e_{3}, e_{4}, e_{5}, e_{6}\right\}\right)$ dengan pewarnaan titik seperti Gambar 4. Pada titik $v_{1}$ bertetangga dengan titik $v_{2}, v_{3}$ dan $v_{4}$, titik $v_{2}$ bertetangga dengan titik $v_{1}, v_{3}$ dan $v_{4}$, titik $v_{3}$ bertetangga dengan titik $v_{1}, v_{2}$ dan $v_{4}$ dan titik $v_{4}$ bertetangga dengan titik $v_{1}, v_{2}$ dan $v_{3}$ sehingga setiap titik memiliki warna yang berbeda, maka banyak warna yang diperlukan untuk mewarnai graf $G$ adalah 4 warna.

\section{BILANGAN TERHUBUNG TITIK PELANGI}

Pada bagian ini dibahas mengenai bilangan terhubung titik pelangi. Sebelumnya, dibahas mengenai definisi titik internal pada Definisi 7 dan lintasan titik pelangi pada Definisi 9.

Definisi 7 [9] Misalkan graf $G$ adalah graf hingga, terhubung dan tak trivial. Jika $P=\left(v_{1}, v_{2}, \ldots, v_{r}\right)$ adalah lintasan pada graf $G$, maka titik $v_{2}, v_{3}, \ldots, v_{r-1}$ merupakan titik internal dari lintasan $P$. Untuk memahami lebih lanjut diberikan Contoh 8 untuk menjelaskan Definisi 7.

Contoh 8 Diberikan graf $G$ seperti Gambar 5 dengan $V(G)=\left\{v_{1}, v_{2}, v_{3}, v_{4}, v_{5}\right\}$ dan jarak terpanjang dari setiap dua titik $(\operatorname{diam}(G))$ adalah 4 . Perhatikan lintasan $v_{1}-v_{5}$, titik internal dari lintasan tersebut adalah titik $v_{2}, v_{3}$ dan $v_{4}$ sebanyak 3 titik, diperoleh dari $\operatorname{diam}(G)-1$.

Definisi 9 [1] Misalkan graf $G$ adalah graf terhubung tak trivial. Suatu lintasan $u-v$ pada $G$ merupakan lintasan titik pelangi jika titik internal pada lintasan $u-v$ untuk setiap $u, v \in V(G)$ memiliki warna yang berbeda.

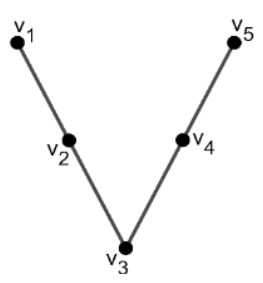

Gambar 5 Graf $H$ dengan 5 Titik 


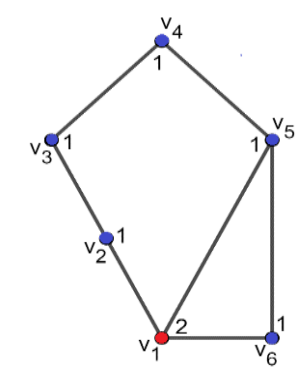

\section{Gambar 6 Pewarnaan Titik Pelangi Graf $G$}

Sama halnya dengan pewarnaan titik di $G$, pada pewarnaan titik pelangi dikaji terkait minimal banyaknya warna dalam pewarnaan. Penjelasan lebih lengkap mengenai minimal banyaknya warna diberikan Definisi 10.

Definisi 10 [1] Pewarnaan titik pada G dikatakan terhubung titik pelangi jika setiap dua titik $u, v$ dihubungkan oleh paling sedikit satu lintasan titik pelangi. Bilangan terhubung titik pelangi dari graf terhubung $G$, dinotasikan dengan $\operatorname{rvc}(G)$ adalah minimal banyaknya warna yang dibutuhkan untuk membuat $G$ terhubung titik pelangi.

Kemudian dari Definisi 9 dan Definisi 10, diberikan Contoh 11 yang diilustrasikan seperti Gambar 6.

Contoh 11 Diketahui graf $G$ dengan $V(G)=\left\{v_{1}, v_{2}, v_{3}, v_{4}, v_{5}, v_{6}\right\}$. Berdasarkan pewarnaan titik pada Gambar 6, diperoleh lintasan untuk semua titik seperti pada Tabel 1. Berdasarkan Tabel 1, terlihat bahwa setiap dua titik $v_{i}, v_{j}$ dengan $i, j \in\{1,2, \ldots, 6\}$ mempunyai lintasan titik pelangi sehingga graf $G$ terhubung titik pelangi dengan banyak warna yang dibutuhkan 2 warna atau $\operatorname{rvc}(G)=2$.

Krivelevich dan Yuster membahas terkait bilangan terhubung titik pelangi pada suatu graf $G$ serta hubungan $\operatorname{rvc}(G)$ dengan diameter yang diberikan pada Teorema 12 .

Teorema 12 [1] Misalkan $G$ graf terhubung tak trivial dengan $n \operatorname{titik,~} \operatorname{maka} \operatorname{rvc}(G) \geq \operatorname{diam}(G)-1$.

\section{Bilangan Terhubung Titik Pelangi pada Graf Kembang Api dan Graf Pembentuknya}

Pada bagian ini, dibahas mengenai keterhubungan titik pelangi pada graf kembang api yang dinotasikan $F_{n, k}$ dengan $n \in \mathbb{N}, n \geq 2$ dan $k=3$. Sebelumnya dikaji mengenai bilangan terhubung titik pelangi pada graf pembentuk dari graf lintasan $P_{n}$ dan graf bintang $S_{n}$.

Teorema 13 [8] Misalkan $P_{n}$ adalah graf lintasan dengan $n$ titik dan $n \in \mathbb{N}$, maka

$$
\operatorname{rvc}\left(P_{n}\right)= \begin{cases}0, & n=2 \\ n-2, & n \geq 3\end{cases}
$$

Teorema 14 [8] Misalkan $S_{n}$ adalah graf bintang dengan $n$ titik dan $n \in \mathbb{N}$, maka

$$
\operatorname{rvc}\left(S_{n}\right)= \begin{cases}0, & n=2 \\ 1, & n \geq 3\end{cases}
$$

\begin{tabular}{|c|c|c|c|c|c|c|}
\hline \multicolumn{7}{|c|}{ Lintasan $u-v$} \\
\hline & $v_{1}$ & $v_{2}$ & $v_{3}$ & $v_{4}$ & $v_{5}$ & $v_{6}$ \\
\hline$v_{1}$ & - & $v_{1}, v_{2}$ & $v_{1}, v_{2}, v_{3}$ & $v_{1}, v_{5}, v_{4}$ & $v_{1}, v_{5}$ & $v_{1}, v_{6}$ \\
\hline$v_{2}$ & $v_{1}, v_{2}$ & - & $v_{2}, v_{3}$ & $v_{2}, v_{3}, v_{4}$ & $v_{2}, v_{1}, v_{5}$ & $v_{2}, v_{1}, v_{6}$ \\
\hline$v_{3}$ & $v_{1}, v_{2}, v_{3}$ & $v_{2}, v_{3}$ & - & $v_{3}, v_{4}$ & $v_{3}, v_{4}, v_{5}$ & $v_{3}, v_{2}, v_{1}, v_{6}$ \\
\hline$v_{4}$ & $v_{1}, v_{5}, v_{4}$ & $v_{2}, v_{3}, v_{4}$ & $v_{3}, v_{4}$ & - & $v_{4}, v_{5}$ & $v_{4}, v_{5}, v_{6}$ \\
\hline$v_{5}$ & $v_{1}, v_{5}$ & $v_{2}, v_{1}, v_{5}$ & $v_{3}, v_{4}, v_{5}$ & $v_{4}, v_{5}$ & - & $v_{5}, v_{6}$ \\
\hline$v_{6}$ & $v_{1}, v_{6}$ & $v_{2}, v_{1}, v_{6}$ & $v_{3}, v_{2}, v_{1}, v_{6}$ & $v_{4}, v_{5}, v_{6}$ & $v_{5}, v_{6}$ & - \\
\hline
\end{tabular}

Tabel 1 Lintasan titik pelangi untuk setiap dua titik pada graf $G$ 


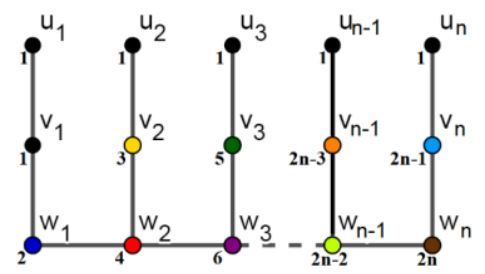

\section{Gambar 7 Graf Kembang Api $\boldsymbol{F}_{n, 3}$}

Teorema 15 Misalkan $F_{n, 3}$ adalah graf kembang api dengan $n \in \mathbb{N}$, maka

$$
\operatorname{rvc}\left(F_{n, 3}\right)=2 n, \quad n \geq 2
$$

Bukti: Graf kembang api $F_{n, 3}$ memiliki $3 n$ titik dan $n-1$ sisi dengan titik $u_{i}, v_{i}, w_{i} \in V\left(F_{n, 3}\right)$ untuk $i=1,2,3, \ldots, n$. Akan dibuktikan $\operatorname{rvc}\left(F_{n, 3}\right)=2 n$, untuk $n \geq 2$. Ilustrasi fungsi pewarnaan tersebut diperlihatkan pada Gambar 7. Dikonstruksikan pewarnaan titik pelangi $c: V\left(F_{n, 3}\right) \rightarrow\{1,2, \ldots, 2 n\}$ yaitu:

$$
\begin{array}{lr}
c\left(u_{i}\right)=1, & i=1,2, \ldots, n \\
c\left(v_{i}\right)=2 i-1, & i=1,2, \ldots, n \\
c\left(w_{i}\right)=2 i, & i=1,2, \ldots, n
\end{array}
$$

Dari konstruksi fungsi perwarnaan titik pelangi $c$ menunjukkan titik pada graf kembang api $F_{n, 3}$ mempunyai warna yang berbeda, kecuali titik $u_{i}$ dan $v_{1}$ dengan $i=1,2, \ldots, n$ namun titik $u_{i}$ bukan merupakan titik internal untuk setiap dua titik pada graf kembang api $F_{n, 3}$. Oleh karena itu, pada konstruksi fungsi pewarnaan titik pelangi $c$ setiap dua titik $x, y \in V\left(F_{n, 3}\right)$ pada graf kembang api $F_{n, 3}$ memiliki lintasan titik pelangi. Sehingga, warna yang dibutuhkan untuk mewarnai semua titik pada graf kembang api $F_{n, 3}$ adalah $2 n$ warna maka diperoleh $\operatorname{rvc}\left(F_{n, 3}\right) \leq 2 n$. Diketahui bahwa $\operatorname{rvc}(G)$ merupakan minimal banyaknya warna yang diperlukan sehingga graf $G$ terhubung titik pelangi. Andaikan $\operatorname{rvc}\left(F_{n, 3}\right)=2 n-1$. Berdasarkan definisi titik internal pada Definisi 7 dan berdasarkan Persamaan (1) setiap lintasan $u_{i}-u_{j}$ dengan $i, j \in\{1,2, \ldots, n\}$ dan $i \neq j$ memiliki paling banyak $n+2$ titik internal. Akibatnya, titik $v_{1}, v_{n}$ dan $w_{i}$ sudah habis diwarnai, sehingga warna yang dibutuhkan untuk mewarnai semua titik pada graf kembang api $F_{n, 3}$ adalah $n+2$ warna, maka tersisa $n-3$ warna. Karena, setiap lintasan $u_{i}-u_{j}$ juga melewati titik $v_{i}$ dan $w_{i}$ dengan $i, j \in\{1,2, \ldots, n\}$, karena titik $v_{i}$ merupakan titik internal, akibatnya warna yang dibutuhkan untuk mewarnai titik $v_{2}, v_{3}, \ldots, v_{n-1}$ adalah sebanyak $n-2$ warna. Tersisa $n-3$ warna, maka terdapat 1 titik $v_{i}$ yang berwarna sama dengan titik yang lainnya. Oleh karena itu terdapat titik $x, y \in V\left(F_{n, 3}\right)$ pada graf kembang api $F_{n, 3}$ yang tidak memiliki lintasan titik pelangi, sehingga pengandaian untuk $\operatorname{rvc}\left(F_{n, 3}\right)=$ $2 n-1$ salah. Dari pengandaian $2 n-1$ warna tidak cukup untuk mewarnai semua titik pada graf kembang api $F_{n, 3}$ maka warna minimal yang dibutuhkan untuk mewarnai graf tersebut adalah $2 n$ warna. Dengan demikian, terbukti bahwa $\operatorname{rvc}\left(F_{n, 3}\right)=2 n$.

\section{Bilangan Terhubung Titik Pelangi pada Graf Kuadratik dari Graf Kembang Api}

Pada bagian ini, dibahas mengenai keterhubungan titik pelangi pada graf kuadratik dari graf kembang api yang dinotasikan $F_{n, 3}^{2}$ dengan $n \in \mathbb{N}$ dan $n \geq 2$.

Teorema 16 Misalkan $F_{n, 3}^{2}$ adalah graf kuadratik dari graf kembang api dengan $n \in \mathbb{N}$, maka

$$
\operatorname{rvc}\left(F_{n, 3}^{2}\right)=\left\lfloor\frac{n}{2}\right\rfloor+1, \quad n \geq 2
$$




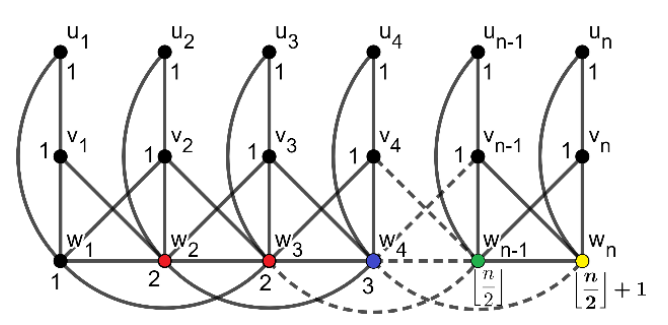

\section{Gambar 8 Kuadratik Graf Kembang Api $F_{n, 3}^{2}$}

Bukti: Kuadratik graf kembang api $F_{n, 3}^{2}$ memiliki $3 n$ titik dan $7 n-5$ sisi dengan titik $u_{i}, v_{i}, w_{i} \in$ $V\left(F_{n, 3}^{2}\right)$ untuk $i=1,2,3, \ldots, n$. Akan dibuktikan $\operatorname{rvc}\left(F_{n, 3}^{2}\right)=\left\lfloor\frac{n}{2}\right\rfloor+1$, untuk $n \geq 2$. Diketahui bahwa $\operatorname{diam}\left(F_{n, 3}^{2}\right)=\left\lfloor\frac{n}{2}\right\rfloor+2$. Berdasarkan Teorema 12, maka diperoleh $\operatorname{rvc}\left(F_{n, 3}^{2}\right) \geq\left\lfloor\frac{n}{2}\right\rfloor+1$. Ilustrasi fungsi pewarnaan tersebut diperlihatkan pada Gambar 8. Dikonstruksikan pewarnaan titik pelangi $c: V\left(F_{n, 3}^{2}\right) \rightarrow\left\{1,2, \ldots,\left\lfloor\frac{n}{2}\right\rfloor+1\right\}$ yaitu:

$$
\begin{aligned}
c\left(u_{i}\right)=1, & i=1,2, \ldots, n \\
c\left(v_{i}\right)=1, & i=1,2, \ldots, n \\
c\left(w_{i}\right)=\left\lfloor\frac{i}{2}\right\rfloor+1, & i=1,2, \ldots, n
\end{aligned}
$$

Dari konstruksi fungsi perwarnaan titik pelangi $c$ menunjukkan warna yang dibutuhkan $\left\lfloor\frac{n}{2}\right\rfloor+1$ warna. Titik pada graf kuadratik dari graf kembang api $F_{n, 3}^{2}$ memiliki warna yang sama untuk titik $u_{i}, v_{i}$ dan titik $w_{1}$ dengan $i \in\{1,2, \ldots, n\}$, titik $u_{1}, u_{2}, \ldots, u_{n}$ bukan merupakan titik internal dari graf kuadratik dari graf kembang api $F_{n, 3}^{2}$, dan titik $v_{1}, v_{2}, \ldots, v_{n}$ merupakan titik internal untuk suatu lintasan titik pelangi tertentu. Sedangkan, titik $w_{j}$ dengan $j \in\{1,2, \ldots, n\}$ merupakan titik internal untuk lintasan $u_{i}-u_{j}, u_{i}-v_{j}, u_{i}-w_{j}, v_{i}-v_{j}, v_{i}-w_{j}$ dan $w_{i}-w_{j+2}$ pada graf kuadratik dari graf kembang api $F_{n, 3}^{2}$. Oleh karena itu, pada konstruksi fungsi pewarnaan titik pelangi $c$ setiap dua titik $x, y \in V\left(F_{n, 3}^{2}\right)$ pada graf kuadratik dari graf kembang api $F_{n, 3}^{2}$ memiliki lintasan titik pelangi, maka diperoleh $\operatorname{rvc}\left(F_{n, 3}^{2}\right) \leq\left\lfloor\frac{i}{2}\right\rfloor+1$ dan $\operatorname{rvc}\left(F_{n, 3}^{2}\right) \geq\left\lfloor\frac{n}{2}\right\rfloor+1$, maka diperoleh $\operatorname{rvc}\left(F_{n, 3}^{2}\right)=\left\lfloor\frac{n}{2}\right\rfloor+1$. Dengan demikian, terbukti bahwa $\operatorname{rvc}\left(F_{n, 3}^{2}\right)=\left\lfloor\frac{n}{2}\right\rfloor+1$

\section{Bilangan Terhubung Titik Pelangi pada Graf Garis dari Graf Kembang Api}

Pada bagian ini, dibahas mengenai keterhubungan titik pelangi pada graf garis dari graf kembang api yang dinotasikan $L\left(F_{n, 3}\right)$ dengan $n \in \mathbb{N}$ dan $n \geq 2$. Graf garis dari graf kembang api memiliki diameter, yaitu:

$$
\operatorname{diam}\left(L\left(F_{n, 3}\right)\right)=n+2
$$

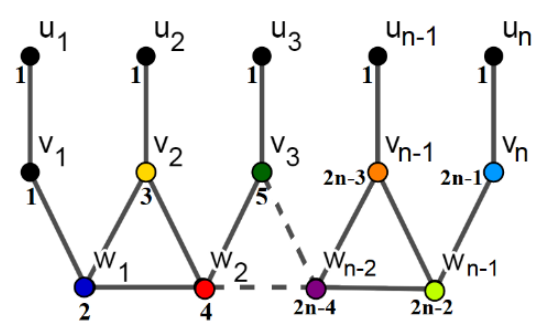

Gambar 9 Graf Garis dari Graf Kembang Api $L\left(F_{n, 3}\right)$ 
Teorema 17 Misalkan $L\left(F_{n, 3}\right)$ adalah graf garis dari graf kembang api dengan $n \in \mathbb{N}$, maka

$$
\operatorname{rvc}\left(L\left(F_{n, 3}\right)\right)=2 n-1, \quad n \geq 2
$$

Bukti: Graf garis dari graf kembang api $L\left(F_{n, 3}\right)$ memiliki $3 n-1$ titik dan $4 n-4$ sisi dengan titik $u_{i}, v_{i} \in V\left(L\left(F_{n, 3}\right)\right)$ untuk $i=1,2, \ldots, n$ dan $w_{i} \in V\left(L\left(F_{n, 3}\right)\right)$ untuk $i=1,2, \ldots, n-1$. Akan dibuktikan $\operatorname{rvc}\left(L\left(F_{n, 3}\right)\right)=2 n-1$, untuk $n \geq 2$. Ilustrasi fungsi pewarnaan tersebut diperlihatkan pada Gambar 9. Dikonstruksikan pewarnaan titik pelangi $c: V\left(L\left(F_{n, 3}\right)\right) \rightarrow\{1,2, \ldots, 2 n-1\}$ yaitu:

$$
\begin{array}{ll}
c\left(u_{i}\right)=1, & i=1,2, \ldots, n \\
c\left(v_{i}\right)=2 i-1, & i=1,2, \ldots, n \\
c\left(w_{i}\right)=2 i, & i=1,2, \ldots, n-1
\end{array}
$$

Dari konstruksi fungsi perwarnaan titik pelangi $c$ menunjukkan titik pada graf garis dari graf kembang api $L\left(F_{n, 3}\right)$ mempunyai warna yang berbeda, kecuali titik $u_{i}$ dan $v_{1}$ dengan $i=1,2, \ldots, n$. Namun titik $u_{i}$ bukan merupakan titik internal untuk setiap dua titik pada graf $L\left(F_{n, 3}\right)$. Oleh karena itu, pada konstruksi fungsi pewarnaan titik pelangi $c$ setiap dua titik $x, y \in V\left(L\left(F_{n, 3}\right)\right)$ pada graf garis dari graf kembang api $L\left(F_{n, 3}\right)$ memiliki lintasan titik pelangi. Sehingga warna yang dibutuhkan untuk mewarnai semua titik adalah $2 n-1$ warna maka diperoleh $\operatorname{rvc}\left(L\left(F_{n, 3}\right)\right) \leq 2 n-1$. Diketahui bahwa $\operatorname{rvc}(G)$ merupakan minimal banyaknya warna yang dibutuhkan untuk membuat $G$ terhubung titik pelangi. Andaikan $\operatorname{rvc}\left(L\left(F_{n, 3}\right)\right)=2 n-2$. Berdasarkan definisi titik internal pada Definisi 7 dan berdasarkan Persamaan (2) setiap lintasan $u_{i}-u_{j}$ dengan $i, j \in\{1,2, \ldots, n\}$ dan $i \neq j$ memiliki paling banyak $n+1$ titik internal.Akibatnya, titik $v_{1}, v_{n}, w_{i}$ sudah habis diwarnai, sehingga warna yang dibutuhkan untuk mewarnai semua titik pada graf garis dari graf kembang api $L\left(F_{n, 3}\right)$ adalah $n+1$ warna, maka tersisa $n-3$ warna. Namun, setiap lintasan $u_{i}-u_{j}$ harus melewati titik $v_{i}$ dengan $i \in\{1,2, \ldots, n\}$ dan $j \in\{1,2, \ldots, n-1\}$, dan titik $v_{i}$ merupakan titik internal untuk lintasan $u_{i}-$ $u_{j}, u_{i}-v_{j}, u_{i}-w_{j}$ sehingga warna yang dibutuhkan untuk mewarnai titik $v_{2}, v_{3}, \ldots, v_{n-1}$ adalah sebanyak $n-2$ warna, maka terdapat 1 titik $v_{i}$ yang berwarna sama dengan titik yang lainnya. Oleh karena itu terdapat titik $x, y \in V\left(L\left(F_{n, 3}\right)\right)$ pada graf garis dari graf kembang api $L\left(F_{n, 3}\right)$ yang tidak memiliki lintasan titik pelangi. Jadi pengandaian $\operatorname{rvc}\left(L\left(F_{n, 3}\right)\right)=2 n-2$ salah, maka haruslah $\operatorname{rvc}\left(L\left(F_{n, 3}\right)\right)=2 n-1$. Dengan demikian, terbukti bahwa $r v c\left(L\left(F_{n, 3}\right)\right)=2 n-1$.

\section{PENUTUP}

Bilangan terhubung titik pelangi pada suatu graf $G$ dinotasikan $\operatorname{rvc}(G)$ merupakan minimal banyaknya warna yang dibutuhkan untuk membuat $G$ terhubung titik pelangi. Graf $G$ terhubung titik pelangi jika titik internal pada lintasan $u-v$ untuk setiap $u, v \in V(G)$ memiliki warna yang berbeda. Berdasarkan penelitian, diperoleh bilangan terhubung titik pelangi pada graf kuadratik dan graf garis dari graf kembang api, beserta graf pembentuknya adalah:

1. Bilangan terhubung titik pelangi pada graf kembang api adalah $r v c\left(F_{n, 3}\right)=2 n, n \geq 2$ dan $n \in \mathbb{N}$.

2. Bilangan terhubung titik pelangi pada graf kuadratik dari graf kembang api adalah $\operatorname{rvc}\left(F_{n, 3}^{2}\right)=$ $\left\lfloor\frac{n}{2}\right\rfloor+1, n \geq 2$ dan $n \in \mathbb{N}$.

3. Bilangan terhubung titik pelangi pada graf garis dari graf kembang api adalah $\operatorname{rvc}\left(L\left(F_{n, 3}\right)\right)=$ $2 n-1, n \geq 2$ dan $n \in \mathbb{N}$. 


\section{DAFTAR PUSTAKA}

[1] Krivelevich, M. dan Yuster, R. The Rainbow Connection of a Graph is (at most) Reciprocal to its Minimal Degree Three. Journal of Graph Theory. 2009; 3: 185-191.

[2] Simamora, D.N.S. dan Salman, A.N.M. The Rainbow (Vertex) Connection Number of Pencil Graph. Internasional Conference on Graph Theory and Information Security. 2015; 74: 138-142.

[3] Chartrand, G.; Lesniak, L.; dan Zhang, F. Graph and Digraph Sixth Edition. Boca Raton, FL: Chapman \& Hall/CRC Press Company; 2016.

[4] Le, V.B. dan Tuy, N.N. The Square of a Block Graph. Discrete Mathematics. 2010; 310: 734-741

[5] Gross, J. L. dan Yellen, J. Graph Theory and Its Applications Second Edition Boca Raton, FL: Chapman \& Hall/CRC Press Company; 2006.

[6] Chartrand, G. dan Zhang, P. Chromatic Graph Theory, Boca Raton, FL: Chapman \& Hall/CRC Press Company; 2009.

[7] Asmiati; Baskoro, E.T.; Assiyatun, H.; Suprijanto, D.; Simanjuntak, R.; dan Uttunggadewa, S. Locating-Chromatic Number of Firecracker Graph. Far East Journal of Mathematical Science. 2012; 43: 1-8.

[8] Dafik; Slamin; dan Muharromah, A. On the (Strong) Rainbow Vertex Connection of Graph Resulting from Edge Comb Product. Journal of Physics. 2018; 1-5.

[9] Arumugam, S.; Hamid, I.S.; dan Abraham, V.M. Decomposition of Graphs into Paths and Cycles. Journal of Discrete Mathematics. 2013; 2013: 1-6.

[10] Hariramkumar, C.S. dan Parvathi, N. Rainbow vertex Coloring for Line, Middle, Central, Total Graph of Comb Graph. Indian Journal of Science and Technology. 2016; 9: 1-6.

[11] Kumala, I. S. dan Salman, A.N.M. The Rainbow Connection Number of a Flower $\left(C_{m}, K_{n}\right)$ Graph and a Flower $\left(C_{3}, F_{n}\right)$ Graph. Internasional Conference on Graph Theory and Information Security. 2015; 74: 168-172.

BRELLA GLYSENTIA VILGALITA : Jurusan Matematika FMIPA UNTAN, Pontianak, brella.glysentia208@gmail.com

YUNDARI

FRANSISKUS FRAN
: Jurusan Matematika FMIPA UNTAN, Pontianak, yundari@math.untan.ac.id

: Jurusan Matematika FMIPA UNTAN, Pontianak, fransiskusfran@math.untan.ac.id 